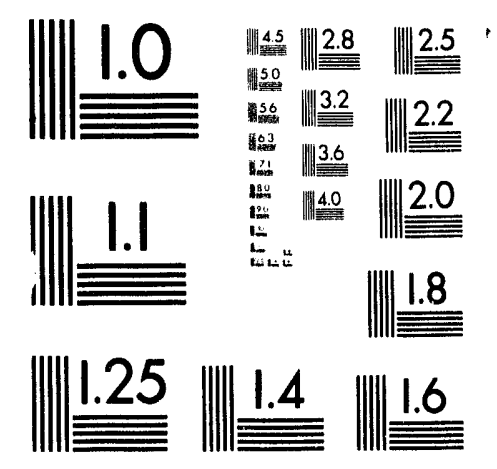



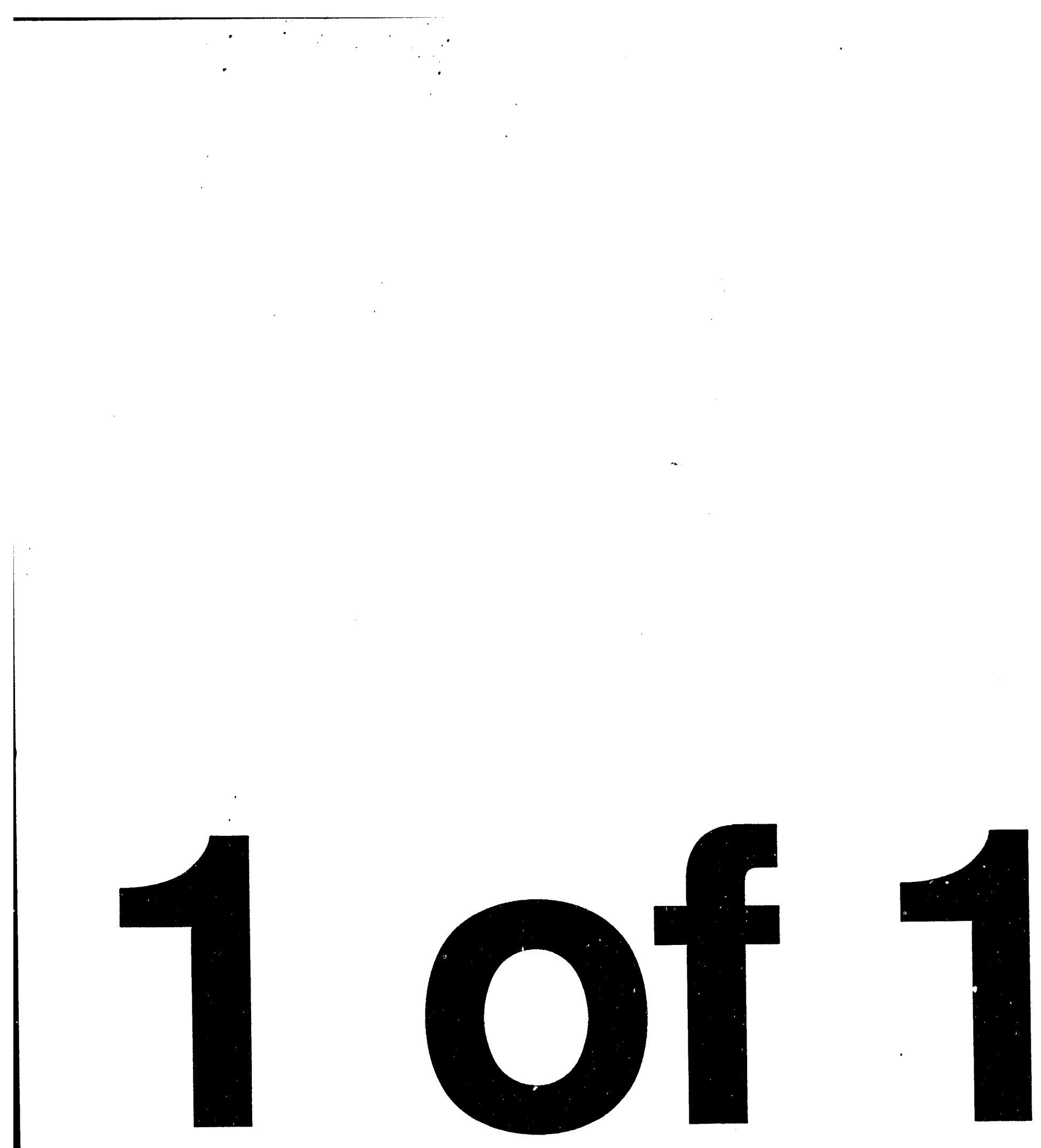

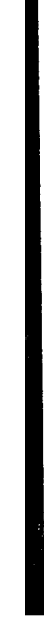

- 


\title{
SP-100 Fuel Pin Performance: Results From Irradiation Testing
}

\section{B. J. Makenas}

D. M. Paxton

Westinghouse Hanford Company

\author{
S. Vaidyanathan \\ Martin Marietta \\ San Jose, Califomia
}

Date Published

September 1993

To Be Presented at Eleventh Symposium on Space Nuclear Power and Propulsion Albuquerque, New Mexico January 9-13, 1994

To Be Published in Proceedings

Prepared for the U.S. Department of Energy

Office of Environmental Restoration and

Waste Management

\section{(2.) Westinghouse}

Hanford Operations and Engineering Contractor for the U.S. Department of Energy under Contract DE-AC06-87RL10930

Copyright Llcense By acceptance of this articte, the publisher and/or recipient acknowledges the U.S. Government's right to retain a nonexclusive, royally-free license in and to any copyright covering this paper.

\author{
C. W. Hoth \\ Los Alamos National Laboratory \\ Los Alamos, New Mexico
}

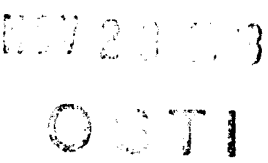


WHC-SA-2091-FP

\title{
SP-100 FUEL PIN PERFORMANCE: RESULTS FROM IRRADIATION TESTING
}

\author{
Bruce J. Makenas and Dean M. Paxton \\ Westinghouse Hanford Company \\ P.O. Box 1970 \\ Richland, WA 99352 \\ (509) 376-5447
}

\author{
Swaminathan Vaidyanathan \\ Martin Marietta \\ P.O. Box 530954 \\ San Jose, CA 95119 \\ (408) $365-6486$
}

\author{
Carl W. Hoth \\ Los Alamos National Laboratory \\ P. O. Box 1663 \\ Los Alamos, NM 87545 \\ (505) $667-2354$
}

\begin{abstract}
A total of 86 experimental fuel pins with various fuel, liner, and cladding candidate materials have been irradiated in the Experimental Breeder Reactor-II (EBR-II) and the Fast Flux Test Facility (FFTF) reactor as part of the SP-100 fuel pin irradiation testing program. Postirradiation examination results from these fuel pins are key in establishing performance correlations and demonstrating the lifetime and safety of the reactor fuel system. This paper provides a brief description of the in-reastor fuel pin tests and presents the most recent irradiation data on the performance of wrought rhenium $(\mathrm{Re})$ liner material and high density UN fuel at goal burnup of 6 atom percent (at. \%). It also provides an overview of the significant variety of other fuel/liner/cladding combinations which were irradiated as part of this program and which may be of interest to more advanced efforts.
\end{abstract}

\section{INTRODUCTION}

The objective of the SP-100 Program is to verify and validate the design of a compact, fast-spectrum nuclear reactor capable of producing 10's to 100's of kilowatts of electrical power in support of a broad range of space applications. The heat source for thermoelectric power generation in the SP-100 reactor design is a core of fuel pins fabricated from high-density uranium nitride (UN) fuel, a rhenium liner, and niobium- $1 \%$ zirconium (Nb$1 \mathrm{Zr}$ ) alloy cladding. The irradiation testing program has provided in-reactor exposure data for proposed SP-100 fuels which are contained within proposed cladding and liner materials. Both FFTF and EBR-II have been utilized to obtain a fast neutron spectrum environment. In most cases, power levels were accelerated through fuel enrichment in order to obtain high burnup data quickly, but in a minority of fuel pins prototypic low power data was obtained, albeit to only low burnup. Reconstitution of tests allowed some pins to reach very high burnups.

Postirradiation examinations were conducted after each test. Nondestructive examinations included neutron radiography, gamma scanning, diameter measurements, gas sampling, metallography, burnup analyses and microprobe analysis. These have allowed the SP-100 Program to assess solid fission product movement, fuel microstructural and dimensional changes, fission gas release to the pin plenum as well as mechanical and chemical interaction between fuel and cladding (or liner).

\section{GENERAL TEST DESIGN}

A typical in-reactor experiment consists of a bundle of fuel assemblies, each containing two capsules. Each capsule consists of an outer stainless steel tube separated by a gas-filled gap from an inner capsule made of TZM (a molybdenum alloy with titanium and zirconium additions). Each TZM capsule is partially filled with lithium (enriched in ${ }^{7} \mathrm{Li}$ ) to simulate the space reactor coolant environment, and contains one test fuel pin. A 
helium cover gas is used over the lithium. During operation, the lithium expands to cover the top, or plenum region, of each pin. The temperature of each fuel pin during irradiation was set by using a specific mixture of helium and argon in the gap between the TZM capsule and the stainless steel capsule to control the conductivity of the gap. The fuel assembly design is shown schematically in Figure 1. Each fuel assembly is approximately one meter long for the EBR-II case and 2.5 meters long for FFTF experiments.

Fuel pins irradiated as part of these tests were 0.15 to $0.33 \mathrm{~m}$ (6 to 13 inches) long and $7.6 \mathrm{~mm}(0.300$ inches) or less in diameter. Fuel columns consisted of a stack of Uranium nitride (Mathews 1992), or occasionally oxide, pellets. Column lengths ranged from 76.0 to $150 \mathrm{~mm}$ (3 to 6 inches). Refractory metal cladding was always utilized and, in a majority of cases (for UN fuel with $\mathrm{Nb}$ based alloy cladding), a metal liner was used between fuel and cladding as a barrier to nitrogen and fission products. The pin design is summarized in Figure 2 with a list of material and design variables given in Table 1. Irradiation conditions were set such that peak cladding temperatures reached 1250 to $1500 \mathrm{~K}$ depending on the goals of a specific test.

TABLE 1. The Range of Variables in SP-100 Fuels Testing Program.

\begin{tabular}{||l|l||}
\hline Pin Geometry Variations & Diameter, Length, Fuel Column Length, Fuel Cladding Gap \\
\hline Fuels Types & UN and UO \\
\hline Variations in UN Fuel & $\begin{array}{l}\text { Density, Enrichment, Stoichiometry, Annular Pellets, Dished Pellets, } \\
\text { and Composition (Carbon and Iron Content) }\end{array}$ \\
\hline Cladding Types & Nb-1Zr, PWC-11, MoRe, Re \\
\hline Liner Configurations & $\begin{array}{l}\text { Free-Standing, bonded, Sealed, Unsealed, Intentional Defects, and No } \\
\text { Liner }\end{array}$ \\
\hline Liner Materials & CVD-W, CVD-Re, Wrought Re \\
\hline
\end{tabular}

\section{SPECIFIC TESTS}

The various fuels experiments and their primary variables are given below. All of them were removed from reactor having achieved their exposure goals and not because of any perceived abnormalities.

SP-1: This first SP-100 in-reactor fuels test was irradiated in EBR-II (Karnesky 1986). It consisted of eight pins, half of which contained low density nitride fuel (87\% of Theoretical Density [TD] UN) while the remainder were fueled with oxide $\left(\mathrm{UO}_{2}\right)$. All were clad with $\mathrm{Nb}-1 \mathrm{Zr}$ and the nitride pins contained a free standing vapor deposited (CVD) tungsten liner between fuel and cladding. Peak cladding temperatures ranged from 1300 to $1500 \mathrm{~K}$. A burnup of slightly less than 1 atom percent was achieved for this test in 96 full power days.

SP-1 Reconstitution: Four of the fuel pins from SP-1 (two oxide and two nitride) continued on for a second round of irradiation in EBR-II. Four fresh pins (two oxide fueled and two nitride) were added to the experiment to reach the full complement. These fresh pins utilized cladding from an early heat of PWC-11 alloy ${ }^{1}$ (essentially $\mathrm{Nb}-1 \mathrm{Zr}$ with $0.1 \%$ carbon) at peak temperatures of 1300 to $1500 \mathrm{~K}$. Liner material for the nitride pins was again tungsten. The fresh pins achieved 3 atom percent bumup while the pins from the earlier SP-1 test achieved 3.9 atom percent burnup in 400 full power days.

SP-2: This test was an eight pin EBR-II experiment which contained four oxide and four nitride fuel pins at peak cladding temperatures of 1300 to $1500 \mathrm{~K}$. The oxide pins were clad with $\mathrm{Nb}-1 \mathrm{Zr}$ while two of the nitride

1 PWC-11 is a register trademark of the Pratt \& Whitney corporation. 


\section{WHC-SA-2091-FP}

pins were clad with Mo-13Re and two with tungsten-lined PWC-11. The test achieved 1.3 atom percent burnup in 181 full power days.

SP-3: This was the first experiment in the EBR-II series to contain high density (96\% TD) UN fuel and all eight pins consisted of this fuel type with $\mathrm{Nb}-1 \mathrm{Zr}$ cladding and tungsten liner. The pins operated to 0.8 atom percent burnup in 112 days at peak cladding temperatures of 1250 to $1500 \mathrm{~K}$.

SP-3R: Six of the fuel pins from SP-3 continued irradiation in this new EBR-II test. Also two nitride pins from the SP-1 experiment were added. These latter low density UN pins were the first to achieve SP-100 goal burnup of 6 atom percent. The remaining higher density UN pins achieved an accumulated burnup of 3.3 atom percent in 469 full power days (The two fuel pins originally from SP-1 were in reactor for 856 days through various tests).

SP-3RR: Four fuel pins which had seen exposure in SP-3 and SP-3R continued irradiation in this EBR-II test (Paxton 1993). In addition to these pins which had tungsten-lined $\mathrm{Nb}-1 \mathrm{Zr}$ cladding, four fresh UN pins with wrought rhenium liners were added. In two cases the rhenium was bonded to the $\mathrm{Nb}-\mathrm{Zr}$ cladding and in the remaining two cases the liners were free standing between fuel and cladding. The high density UN fuel pins from the original SP-3 experiment achieved 6 atom percent burnup in this test while the fresh rhenium lined pins attained 3.1 percent in 429 full power days.

FSP-1: This test of 38 fuel pins was irradiated in FFTF for 269 full power days (Lyon 1992). All of the fuel pins contained UN fuel. Fuel pellets of various densities, geometries, and enrichments were utilized. All pins had $\mathrm{Nb}-1 \mathrm{Zr}$ cladding with free standing CVD tungsten or free standing CVD rhenium liners. Two different cladding outer diameters, $5.84 \mathrm{~mm}$ and $7.62 \mathrm{~mm}$ (0.230 and 0.300 inches), were represented. Pins were more than twice as long as the six inches typical of pins irradiated in EBR-II. The majority of fuel pins in this test achieved 2.3 atom percent burnup with some very low enrichment (prototypic power) fuel pins achieving only 0.5 percent burnup.

FSP-1R: This continuation of the FSP-1 test in FFTF contained 22 previously irradiated fuel pins and 16 fresh pins. The new additions all contained high density UN fuel and most utilized wrought rhenium liners (free standing or bonded) with $\mathrm{Nb}-1 \mathrm{Zr}$ cladding. Two of the new arrivals however utilized bare rhenium cladding. The pins continuing from FSP-1 achieved an accumulated burnup of 5.6 atom percent burnup while the fresh pins attained 3.1 percent.

FSP-1RR/SP-4: One additional fuels test (Webb 1993) has been partially constructed but not yet irradiated. It was designed to either add 4 fresh pins to a 38 pin continuation of the FFTF series or to function as a solitary 4 fuel pin EBR-II test. Two pins in this test contain the usual fuel column of high density UN but also have a small stack of BeO pellets to act as an integral reflector. A third pin contains internal and external passive temperature monitoring devices while a fourth pin contains an unusually small fuel/liner gap to study interaction strains occurring during irradiation. If these fuel pins are combined with previously irradiated fuel pins, accumulated burnups of 9-10 atom percent would be possible on the most geriatric residents of the experiment.

Other more advanced fuel tests have been proposed to more correctly simulate the SP-100 environment. A flowing lithium loop experiment intended for residence in FFTF was the target of considerable design effort but did not reach the fabrication stage.

\section{POSTIRRADIATION EXAMINATION RESULTS}

Fuels: The oxide fuels were examined only at low burnup due to program focus on nitrides. The oxide pellets performed satisfactorily with the expected restructuring, radial cracking and grain boundary porosity (Figure 3 ). Early nitride fuels were initially low density and tended to show a very porous region at the pellet-pellet interfaces (Figure 4). Very little restructuring or cracking were observed. Later higher density UN fuels were employed. The most recent results from the SP-3RR test (shown in Figure 5) have demonstrated unencumbered 


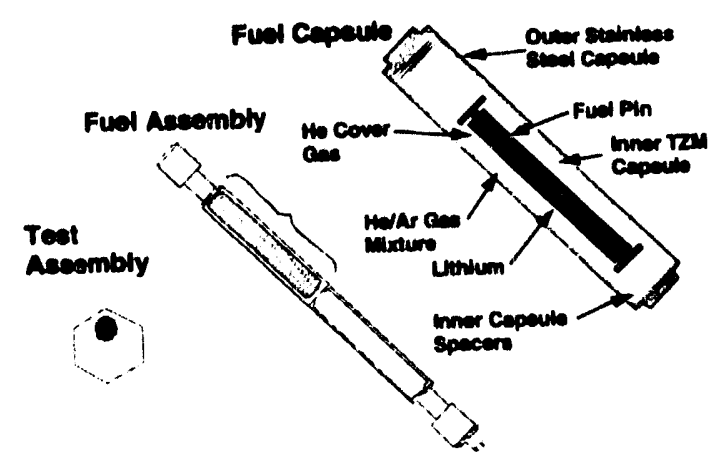

FIGURE 1. Capsule Geometry for In-reactor Fuel Pin Test

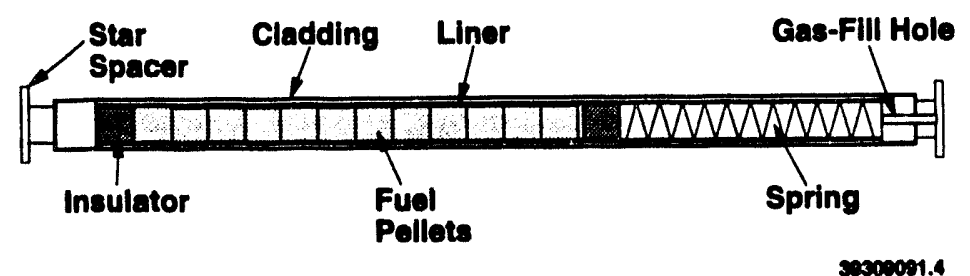

FIGURE 2. Geometry of Fuel Pin Tested in the Irradiation Testing Program

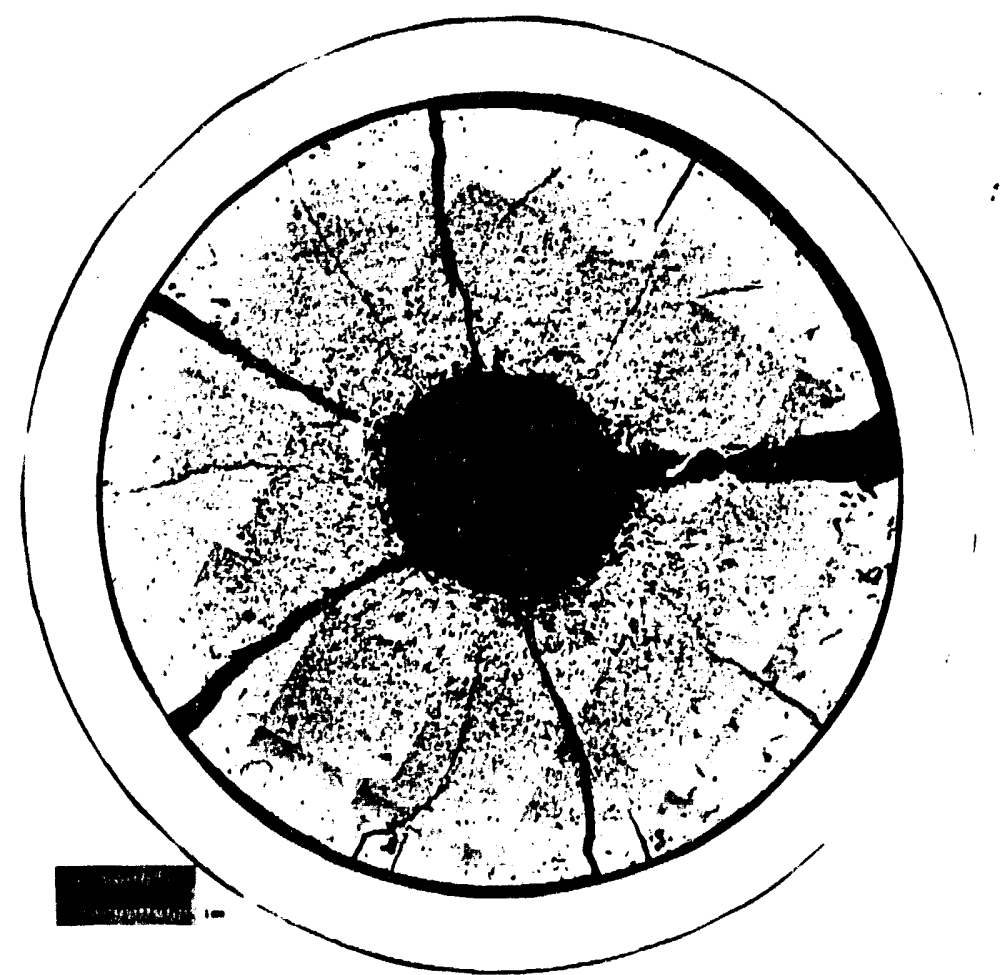

FIGURE 3. Oxide Fuel at 1 Atom Percent Bumup Irradiated in Concert with Nb-1Zr Cladding (SP-1 Test) 
performance out to 6 atom percent burnup. Other than microscopic grain boundary voids (Figure 6) and some fusing of pellets at interfaces, major structural changes have not occurred in the high density fuel pellets. Variations in fuel iron content were addressed in early tests and found to be benign. Pins with annular fuel, dished pellets, altered carbon contents, etc. have been examined by nondestructive techniques (Figure 7) only but appear to have performed without incident.

Fission gas release: Data on release of fission gases from fuel pellets was acquired through the puncturing of pin plena and analysis of recovered gases. Releases from Uranium Nitride fuel have been low with respect to the expected behavior of oxide fuels. The data gathered for nitride fuel (Figure 8) has indicated that the higher density fuels release less gas to the plenum of an SP-100 fuel pin as compared to low density UN.

Solid Fission Product Migration: In the earliest SP-100 irradiation tests, metallography, radiography, and gamma scanning (Figures $9 \& 10$ ) demonstrated that in low density UN metallic fission products such as Ru tend to migrate to the outer surface of pellets near the interface between two pellets. Cesium tends to migrate in high and low density UN fuels (and in oxides) to the cooler ends of the fuel column and to pellet interfaces.

Cladding and Liner Behavior: In all cases the $\mathrm{Nb}-1 \mathrm{Zr}$, MoRe, PWC-11 and Re cladding have performed well. In the case of Re clad pins, recent neutron radiography has shown apparent unbreached performance out to 3 atom percent burnup in UN (Figure 7). For the other cladding types metallography is available which lends additional confidence in performance. For low burnup pins in which the fuel has not swelled to contact the cladding, no diameter increase is observed. The same is true for pins fabricated with an intentionally large fuel/liner/cladding gap. When diameter increases have occurred in UN pins, local peaks are usually apparent in the data (Figure 11). These correspond to the center of pellets for high density UN and to fission product accumulations at pellet corners for low density UN. Most recent results from Re lined pins with $\mathrm{Nb}-1 \mathrm{Zr}$ cladding (at 3 atom percent burnup in the SP3RR test) show no diameter change for pins with bonded liner/cladding and small changes for those with free standing liners (Figure 12). Peak diameter changes for pins at goal 6 atom percent burnup have been slightly less than 2 percent (Figure 13). In general wrought Re liners have shown better performance (from a ductility and porosity point of view) than CVD Re liners and both have out performed CVD tungsten liners. In bonded cladding the liner/cladding interface has shown excellent adhesion during irradiation (Figure 14).

\section{CONCLUSION}

The SP-100 fuels testing program has been both focused and wide-ranging. It has succeeded in producing data which supports a specific fuel pin design that has proved to be more than adequate for the space reactor core as we currently envision it. The UN (high density) fuel with rhenium liner bonded to $\mathrm{Nb}-1 \mathrm{Zr}$ cladding has demonstrated superior performance. But the in-reactor fuel tests have yielded more than just information on one material system. Information on the behavior of fuel pellets with various densities, with various geometries, and with various compositions and stoichiometries has been forth coming. Oxide fuel with high temperature cladding bas been studied. Several cladding alloys and liner configurations have been utilized giving valuable insights on high temperature compatibility and stability issues. The work performed as part of this irradiation program will likely benefit not only those future projects which seek to build an SP-100 style reactor but also other design efforts which will likely go beyond the current capabilities.

\section{Acknowledgments}

SP-100 Irradiation tests were fabricated and performed by Westinghouse Hanford Company under contract with the Department of Energy. Fuel pins for these tests were made at Los Alamos National Laboratory. Postirradiation examinations were performed at Pacific Northwest Laboratory's hot cells in Richland, Washington, and at the Hot Fuels Examinations Facility in Idaho Falls, Idaho. Significant contributions were made by many people over the last several years including designers, fabricators and hot cell personnel. Prominent amoung these were Rick Mason and Bruce Mathews at LANL and Dale Dutt, Janell Hales, and Richard Karnesky at Hanford. 


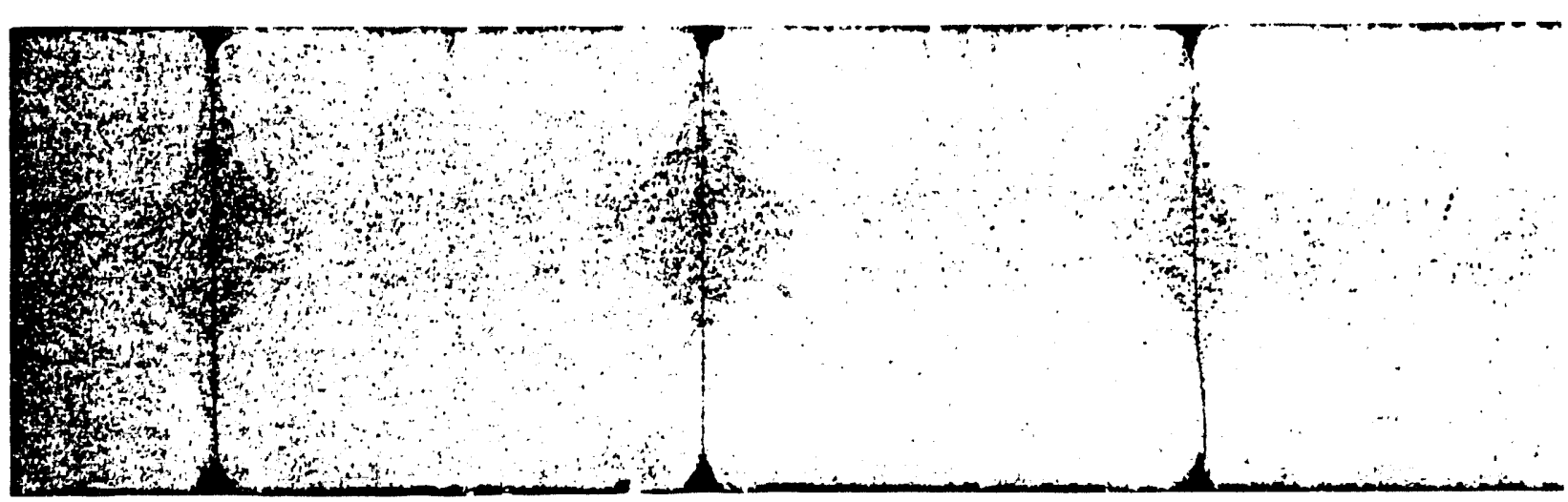

FIGURE 4. Longitudinal Crossection of Low Density UN Fuel Pellets at 6 Atom Percent Burnup (SP3R Test)

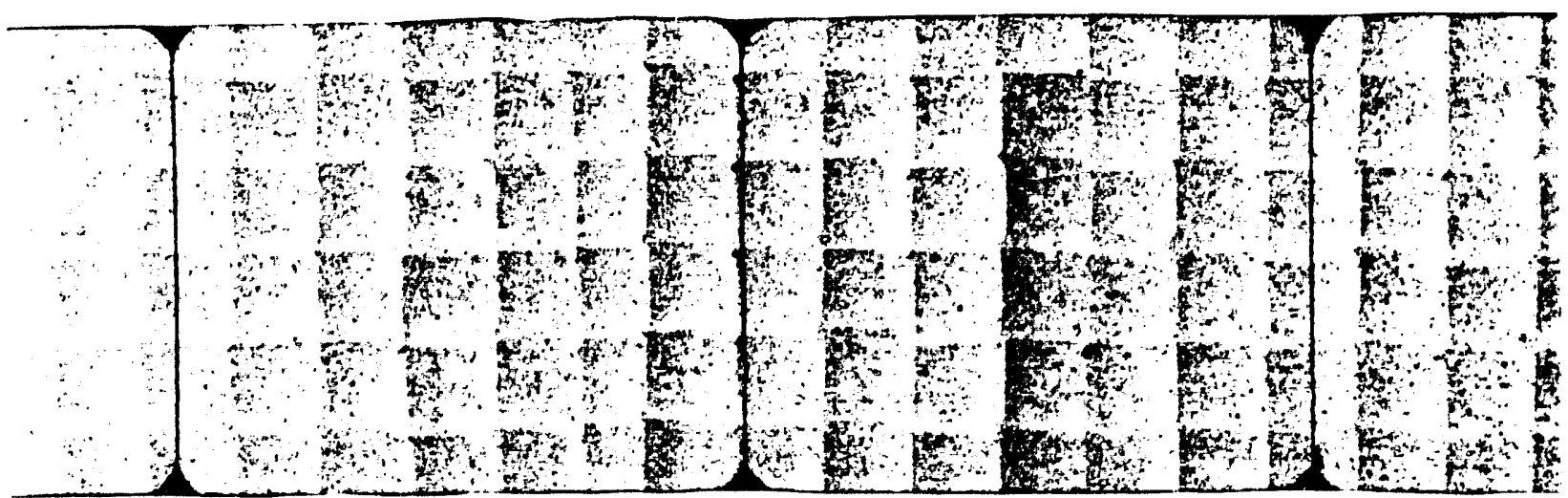

FIGURE 5. Longitudinal Crossection of High Density UN Fuel Pellets at 6 Atom Percent Bumup (SP3RR Test)

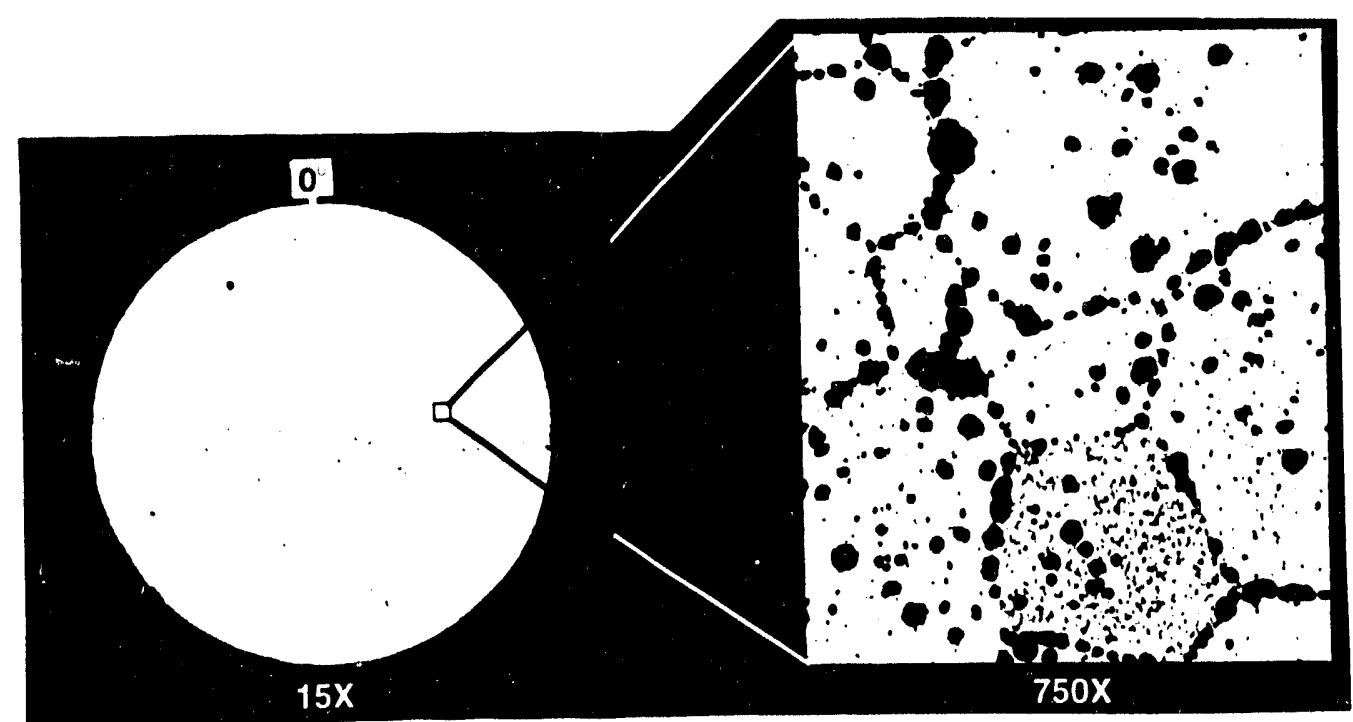

FIGURE 6. Fuel Structure in High Burnup (6 atom percent) High Density UN Fuel Showing Porosity at Grain Boundaries (SP3RR Test) 

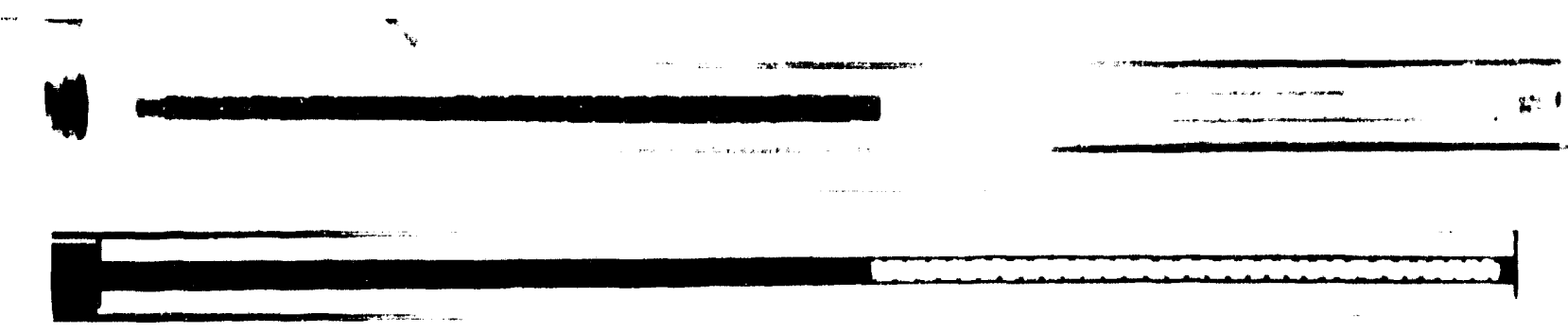

FIGURE 7. Neutron Radiography of Irradiated SP-100 UN Fuel Pins From the FSP-1R Test Upper pin is at 6 atom percent burnup with annular fuel, W-liner and $\mathrm{Nb}-1 \mathrm{Zr}$ Cladding. Lower pin is at 3 atom percent burnup with Rhenium cladding.

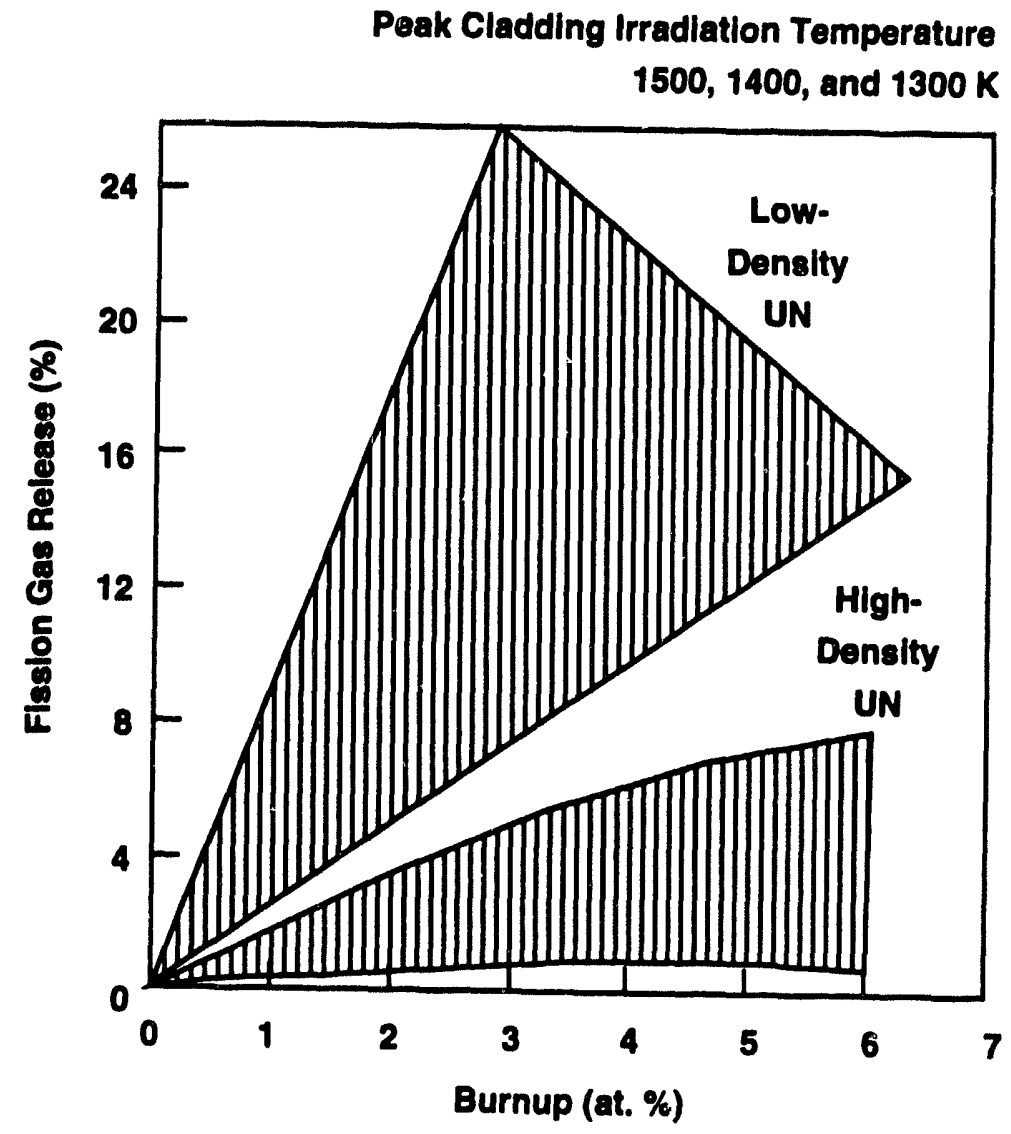

39309091.7

FIGURE 8. Gas Release Results From Irradiated UN Fuel Pins 


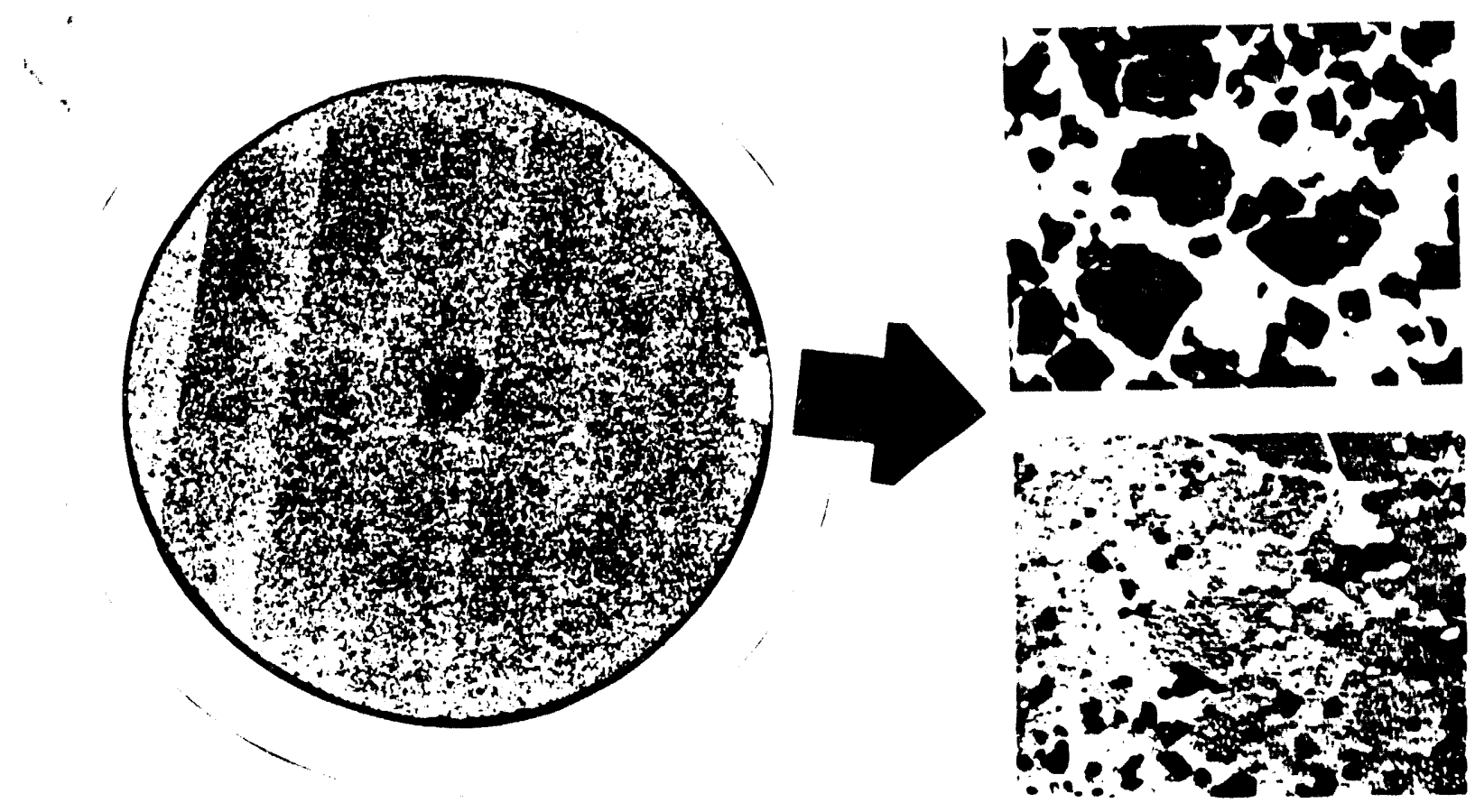

FIGURE 9. Crossection (near pellet/pellet interface) of Low Density UN Fuel in MoRe Cladding. Note local accumulations of fission products and the central void. Burnup is 1.4 atom percent (SP-2 Test)

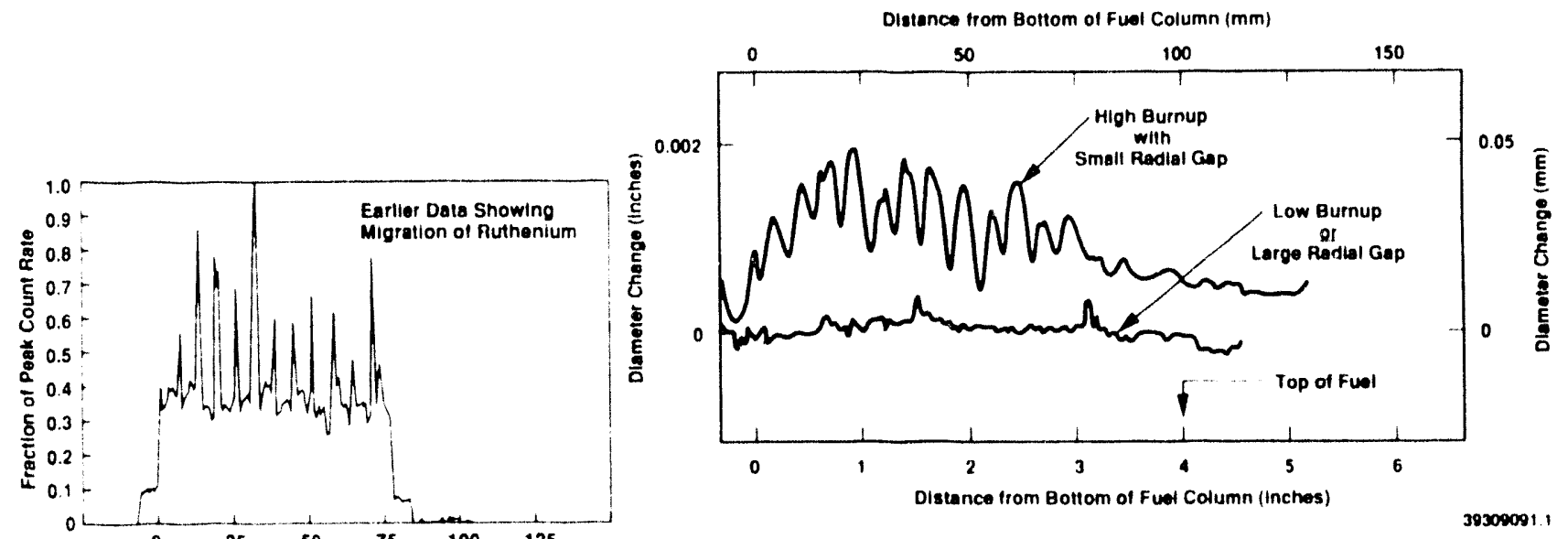

FIGURE 11. Diameter Changes in SP-100

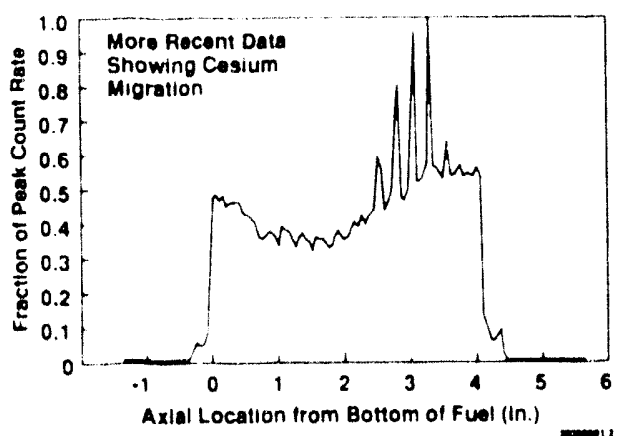

Pins From the FSP-1 Test

FIGURE 10. Gamma Scanning Results From SP-100 UN Fuel Columns.

Early data is low density UN fuel and later data is high density. 
WHC-SA-2091-FP

$\mathrm{mm}$ from bottom of fual

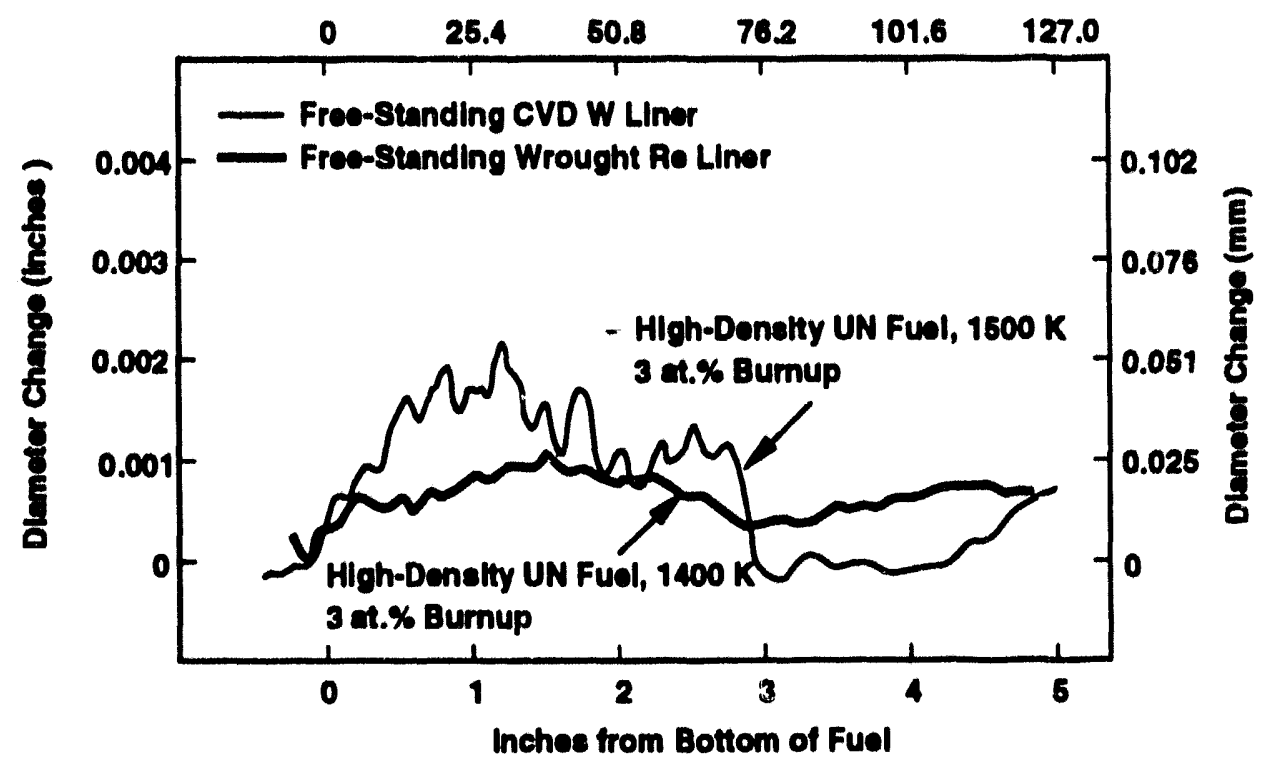

FIGURE 12. Diameter Changes in UN Fuel Pins with 3 Atom Percent Bumup. Re lined Pin was Irradiated in the SP3RR Test. $\mathrm{mm}$ from Bottom of Fuel

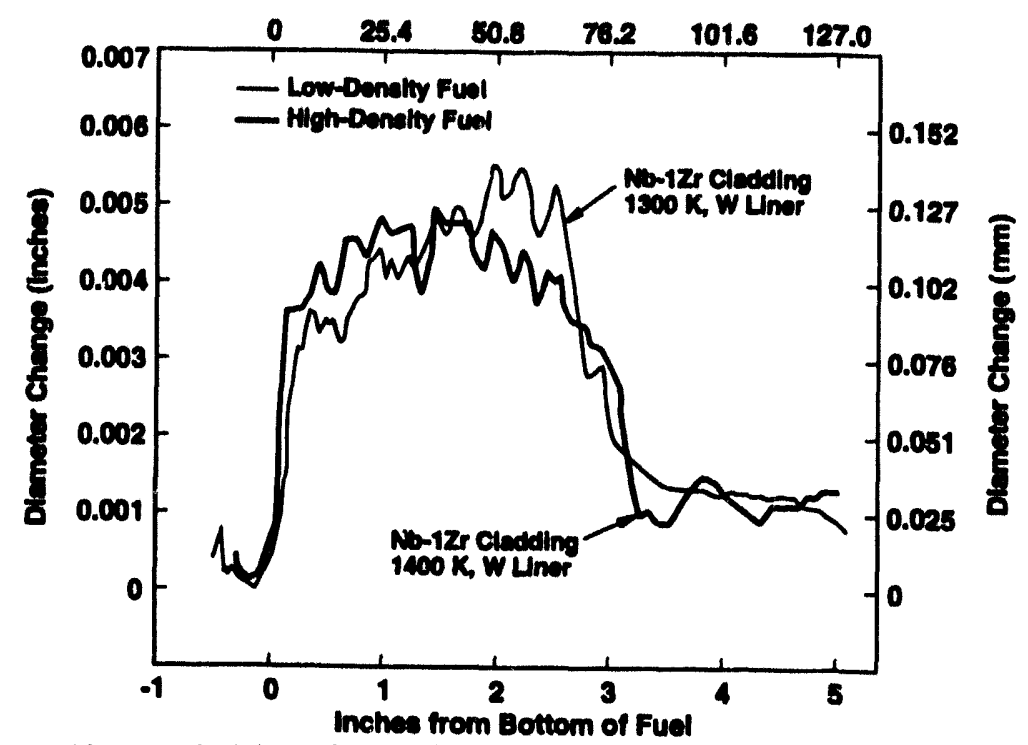

FIGURE 13. Diameter Changes in Pins with High Density or Low Density UN Fuel at 6 Atom Percent Burnup (SP3R \&SP3RR Tests)

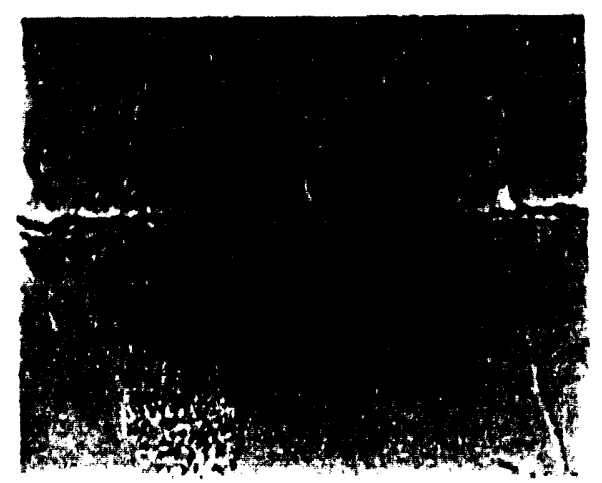

FIGURE 14. Rhenium/Nb-1Zr Interface in Irradiated Bonded Cladding (SP3RR test) 


\section{References}

Hales, J. W., B. J. Makenas and D. S. Dutt (1989) "SP-100 Fuel Pin Irradiation Testing," in Trans of the 6th Symposium on Space Nuclear Power Systems, CONF-890103-Summs., M. S. El-Genk and M. D. Hoover, eds., University of New Mexico's ISNPS, Albuquerque, NM, 1: 136-140.

Karnesky, R. A. and R. E. Mason (1986) "Postirradiation Examination Results from SP.1." in Third Symposium on Space Nuclear Power, CONF-860102-Summs., M. S. El-Genk and M. D. Hoover, eds., University of New Mexico's ISNPS, Albuquerque, NM.

Lyon, W. F. (1991) "Thermal Analysis of the FSP-1 Fuel Pin Irradiation Test," in Proc. 8th Symposium on Space Nuclear Power Systems, CONF-910116, M. S. El-Genk and M. D. Hoover, eds., American Institute of Physics, New York, AIP Conference Proc. No 217, 2: 892-901.

Makenas, B. J., J. W. Hales and A. L. Ward (1991) "Fuels Irradiation Testing for the SP-100 Program," in Proc. 8th of the Symposium on Space Nuclear Power Systems, CONF-910116-Summs., M. S. El-Genk and M. D. Hoover, eds., American Insticute of Physics, New York, AIP Confernece Proc. No 217, 2: 886-891.

Mathews, R. B. (1992) "Ceramic Fuel Development for Space Reactors," Ceramic Bulletin No. 1, 71: 96-101.

Paxton, D. M. and B. J. Makenas (1993) "SP-100 Fuel Pin Performance Results from the SP-3RR Irradiation Test, " in Trans. American Nuclear Society, 68A: 325-326.

Webb, R. H. and W. F. Lyon, "Thermal Analysis of the FSP-1RR Irradiation Test," in Tenih Symposiun on Space Nuclear Power and Propulsion, CONF-930103, 1: 259-266. 
WHC-SA-2091-FP

\title{
DISTRIBUTION
}

\author{
External \\ No. of Copies \\ 2 \\ Department of Energy - Headquarters \\ L. L. Rutger \\ NE-52 \\ K. A. Shaw \\ NE-52 \\ 2 \\ Department of Energy - Richland Operations Office \\ O. A. Farabee \\ N1-39 \\ R. G. Hastings \\ N1-39 \\ 1 \\ Department of Energy - San Francisco \\ K. Reiley \\ 5 \\ Los Alamos National Laboratory \\ J. Buksa \\ K. E. Chidester \\ C. W. Hoth \\ R. B. Mathews \\ M. G. Parker \\ 4 \\ Martin Marietta - San Jose \\ S. Bailey \\ G. Kruger \\ R. Murata \\ S. Vaidyanathan \\ 1 \\ Pacific Northwest Laboratory \\ D. J. Deschane \\ P8-24 \\ 1 \\ University of Florida \\ 701 SW 62nd Blvd, Apt. GG-240 \\ Gainesville, FL 32607 \\ D. M. Paxton
}




\section{WHC-SA-2091-FP}

\section{DISTRIBUTION}

$\underline{\text { Internal }}$

Westinghouse Hanford Company

F. E. Bard

L5-01

E. J. Bitten

L4-73

D. S. Dutt

L6-39

E. W. Gerber

L5-62

R. D. Leggett

H0-40

B. J. Makenas (3)

L5- 02

R. P. Omberg

$\mathrm{H} 0-40$

A. E. Waltar

H0-32

Central Files

L8-04

Publication Services (3)

L8-07 

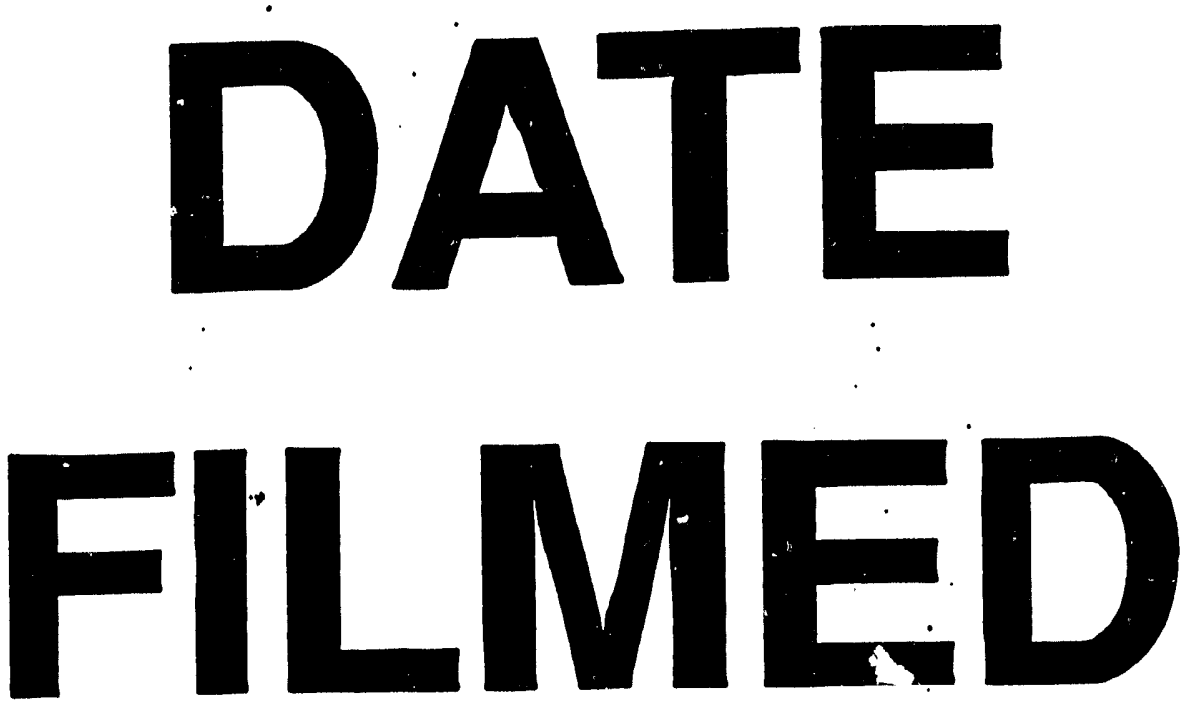

$1 / 26 / 94$
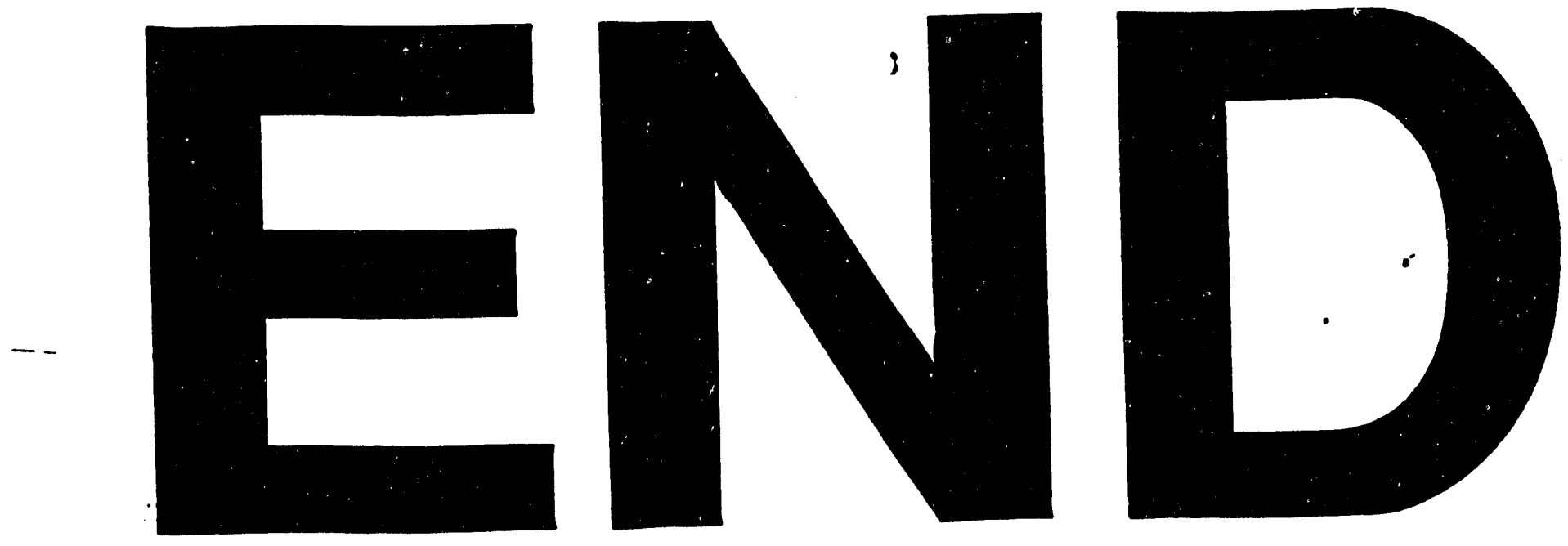
